\title{
ANALYSIS OF PREVALENCE AND FACTORS INFLUENCING ADOLESCENT IDIOPATHIC SCOLIOSIS AMONG SCHOOL STUDENTS IN THIRUVALLUR DISTRICT
}

\author{
${ }^{*}$ Janani $\cdot \mathbf{R}$ \\ ${ }^{1}$ Arunachalam Ramachandran \\ ${ }^{2}$ Divya.S
}

\section{ABSTRACT}

Background: The occurrence of AIS is on a high, which necessitates preventive measures at the earliest for which screening is essential at the school level. Prevalence of AIS around the world is 0.4- 5.2\%. Scoliosis leads to problems such as cosmetic deformity, quality of life, visible disability, backache, personal growth, autonomy, and reduced respiratory function. These problems can be prevented if scoliosis is diagnosed and treated earlier. To screen for AIS among selected schools and to analyze factors influencing adolescent idiopathic scoliosis.

Methods: A total of 3250 Students between age 11 to 15 years were screened for AIS from Thiruvallur district. The screening was performed at two levels using Adam's forward bend test and scoliometer, respectively. A detailed analysis was performed on symptomatic AIS subjects $(\mathrm{n}=58)$ for various influencing factors and determinants.

Results: The prevalence of AIS from $11-15$ years was $0.27 \%, 0.30 \%, 0.49 \%, 0.36 \%$ and $0.33 \%$ respectively. AIS-affected thoracic region (50\%) of females (58\%) with a predominant right sided curvature (55\%). Bag type and weight, sitting posture in a classroom, study posture was found to influence AIS.

Conclusion: This study emphasizes early screening of AIS for school children at the age of 11- 15 years based upon the high prevalence rates compared to global standards. Parents and teachers should be aware of the bag type and weight, sitting and studying posture for early prevention of AIS.

Keywords: AIS, prevalence of AIS, FBT, scoliometer, scoliosis, school screening.

Received $19^{\text {th }}$ February 2019, accepted $25^{\text {th }}$ May 2019, published $09^{\text {th }}$ June 2019

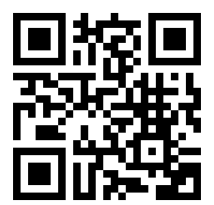

www.ijphy.org 10.15621/ijphy/2019/v6i3/183877

\footnotetext{
${ }^{1}$ M.P. T (Neuro), Ph.D, Professor and Principal

Madhav college of physiotherapy, Madhav University.

Email: Arunstar19@gmail.com

${ }^{2}$ Assistant Professor, Meenakshi Academy of Higher

Education and Research.
}

\section{CORRESPONDING AUTHOR}

${ }^{* 1}$ Janani .R

Master of Physiotherapy (Pediatrics)

Assistant Professor, Faculty of Physiotherapy,

Meenakshi Academy of Higher Education and

Research. Email: Janani15r@gmail.com 


\section{INTRODUCTION}

Adolescent idiopathic scoliosis (AIS) is prevalent in 4 among 100 adolescents, which have been the most common type seen in children affecting from ages 10 to 18 . Prevalence of AIS around the world is $0.4-5.2 \%$. The rate of prevalence of AIS in young children is disseminated similarly between the genders, yet there is a female prevalence of $90 \%$ among ten years old. Scoliosis is distinguished by magnitude, location, and etiology. As indicated by the scoliosis research society (SRS), the scoliotic curve might be idiopathic, neuromuscular, or congenital. Congenital scoliosis is caused because of failure in somite development or division. Neuromuscular scoliosis happens as a result of lesions in the motor neuron. Pediatric scoliosis is a rare condition observed by regular spine screenings performed either by a nurse or a pediatrician or child presenting with altered stature [1].

Idiopathic scoliosis occurs due to unknown etiology. There are two major types of curves: structural and non-structural. A non-structural curve completely rectifies clinically and radiographically on parallel twist toward the apex of the curve and needs vertebral pivot. A non-structural curve is typically nondynamic and is regularly brought about by shortened lower limb on the side of curve's apex. It is fundamental to pursue these curves amid development because sometimes they may form into structural curves. A structural curve can't be intentionally, inactively, or persuasively completely corrected. The pivot of the vertebrate is available towards the convexity of the curve. A fixed thoracic noticeable prominence or rib hump in a child or a lumbar paraspinal prominence is continuously observed $[2,3]$.

Scoliosis leads to problems such as cosmetic deformity, poor Quality of Life, direct disability, pain in the thoracic and lumbar region, affects Psychological Well Being, progresses to Adulthood, leading to Breathing dysfunction. These problems can be prevented if scoliosis is diagnosed and treated earlier. Scoliosis screening detects people who have scoliosis, is diagnostic uncertainty, which also refers to positive findings for further assessment. Hence regular scoliosis Screening must be performed in school going children [4].

The Scoliosis Research Society task force agreed upon the use of a scoliometer as a valid quantitative measure with 5-7 degrees of deformity along with the Adam's Forward Bend Test as a threshold for positive screening [5-7]. In recent times, there are very few school screening programs being conducted in South India. Hence, objectives of scoliosis school screening program are to prevent the progression of spinal deviations that can affect student's health. As it is difficult to avoid the occurrence of scoliosis, early discernment and medical care will prevent the complications of scoliosis and screening programs enhances understanding and creates awareness of this disease among parents and teachers. Therefore, this study aims to find the prevalence of AIS and factors influencing AIS among school going children in Thiruvallur district.

\section{MATERIALS AND METHODS}

This study was done targeting Thiruvallur district for logistic feasibility from November 2016 till August 2017. The screening was conducted at middle school and high school of Thiruvallur district. A total list number of schools and the total number of students in Thiruvallur district were collected from the community department of Saveetha hospital. All the schools were approached through proper channel either in person or by telephone for obtaining permission to conduct the screening program.

The study was presented to the Institutional Ethical Committee, Saveetha University, and got clearance (Ref No: 007/11/2016/IEC/SU). In this screening program, students aged 11-15 years were included. Any student with other orthopedic, neurological, and systemic disorder that may interfere with the study results (perceived by the researcher) was excluded. There were about 112 government schools. Out of 112 schools, 80 schools were approached personally or telephonic communication the remaining schools did not have proper communication details. Thirty-two schools accepted to provide permission for the same.

Out of 32 schools, 16 schools were randomly selected using simple random sampling (lottery) method. The screening details were furnished to the CEO of Thiruvallur district in person. All the school principals and teachers were detailed briefed and explained regarding the aims, study's intentions, the clinical importance of early detection, methods, and procedure using a PowerPoint Presentation before the screening program commenced. The parents were also informed about the screening program through school teachers well in advance. Informed consent was obtained from the school management and respective class teachers.

\section{Screening phase}

The data collection was done for a period of 7 months from December 2016 to June 2017. A total of 3250 students were screened over 24 days. Two physiotherapists were involved in the screening process for scoliosis at their school premises during the time allotted by the school management. Each student was screened separately, giving due to privacy.

\section{Step 1}

The procedure began with collecting demographic data from the students followed by visually observing the student's spine in standing in a straight position, with their back facing the therapist, head in neutral with eyes looking forward with the arms relaxed by the sides. With the student in this position, any asymmetries in both the shoulder, prominence of scapula, unequal waistline or distance between arms, and lower limb length discrepancy were checked.

\section{Step 2}

Scoliometer was used to determine ATR along with Adam's FBT for students who were observed to have scoliosis while allowing the arms to be relaxed by the sides in a direction where the palms were facing inwards in a relaxed manner. Adam's FBT was performed by instructing the student to 
slowly bend in a forward manner until the shoulders are level with the hips. The examiner viewed the student from the back with eyes at the same level as the back. Height of the Bending position was adjusted, so the deformity of the spine is most pronounced. The scoliometer was placed across the deformity at right angles (on the spinous process at curve apex level) to the body, with the marking centered over the curve and the angle was recorded. The students were observed in both sagittal and frontal view. This process took place for approximately 5 minutes for each one child. Students who were negative from Adam bend test were labeled as functional scoliosis.

\section{Step 3}

The students who had an ATR of $5^{\circ}$ or more on the scoliometer were further referred to Saveetha Hospital for detailed evaluation and management and were informed to their parents. The students who had structural scoliosis were sent a notification form regarding the positive findings, and further, they were referred to orthopedician in Saveetha hospital, if necessary was follo8/wed by a whole spine anteroposterior and lateral radiograph for diagnosis. Information regarding the following was also collected: Age of menarche for the girls, Family history, History of back pain, Schoolbag type, Schoolbag weight, Posture during studying, sleeping posture and Sitting posture in the classroom.

\section{Functional scoliosis}

Students who were found to have functional scoliosis were assessed for systemic causes, limb length inequality, and other contributing factors apart from the abnormal posture. Students who were perceived to have developed scoliosis due to postural reasons were educated regarding the exercises and postural correction to prevent further progression of the problem.

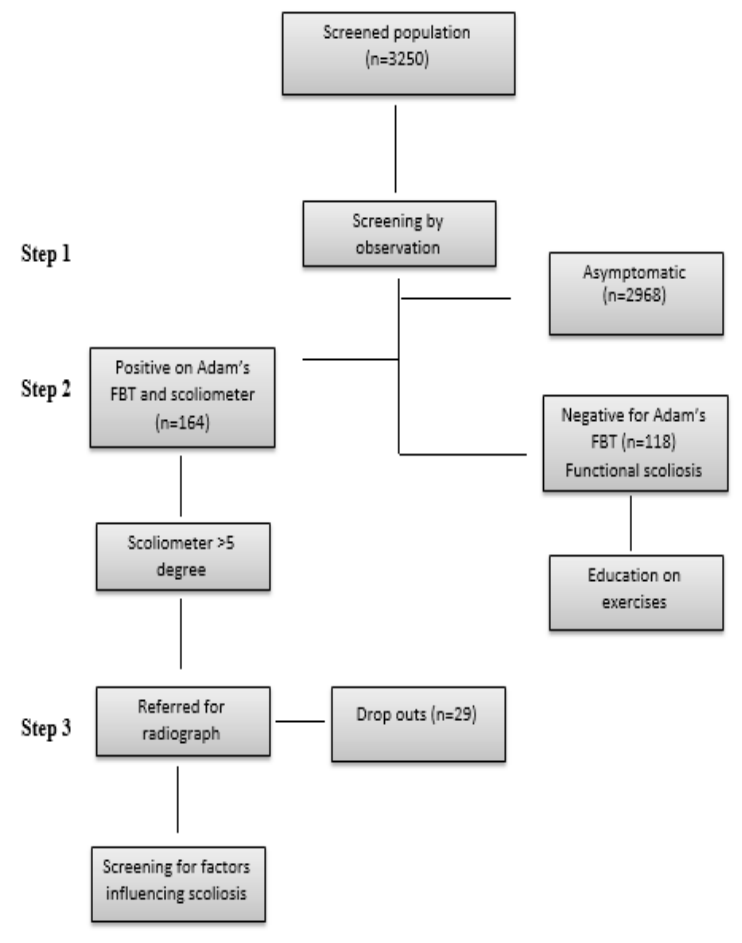

\section{RESULTS}

\section{Prevalence}

A total number of 3250 students were screened for the study, among which 282 students were suspected to have scoliosis. Further out of the $48.2 \%$ of the students were female, and $51.8 \%$ were male. The distribution of age among total screened are displayed in table 1. Gender distribution among various age categories is presented in table 1 .

One hundred sixty-four students were to be positive in Adams FBT and scoliometer; they were referred to Saveetha hospital for Saveetha hospital. Among the students referred to hospital, 29 students did not come to the hospital for further evaluation. One hundred thirty-five students participated in step 3 of the screening phase, and 58 were found positive for structural scoliosis by X-ray analysis. $118(3.6 \%)$ of the screened population were found to have functional scoliosis. Out of which, 44 (37.2\%) students were at the age of 13 years, which was significantly more than other age categories. $1.78 \%$ of students were found positive for Adolescent idiopathic scoliosis from 3250 students.

\section{Age and gender- Prevalence}

Out of 58 students found positive for AIS in radiograph, 9 $(15.5 \%)$ students were at the age of 11 years, $10(17.2 \%)$ students were at the age of 12 years, 16(27.5\%) students were at the age of 13 years, $12(20.6 \%)$ students were at the age of 14 years and 11 (18.9\%) students were at the age of 15 years which is represented in graph 3. Prevalence of AIS from 11 to 15 -year-old students were $0.27 \%, 0.30 \%, 0.49 \%, 0.36 \%$ and $0.33 \%$, respectively. Male to female ratio was found to be 1:1.2 (11 years and 12 years), 1:2.2 (13 years), 1:1.1 (14 and 15 years) which is represented in table 2.

\section{Curve characteristics- Prevalence}

Among the screened positive for AIS, 32(0.98\%) students had a right side curve, and $26(0.8 \%)$ had a left side curve. The predominant curve location for AIS in students was on the thoracic spine $29(0.89 \%)$ followed by thoracolumbar $19(0.58 \%)$ and the least was lumbar 10 (0.3\%). Majority students among screened positive for AIS had a single curve $34(1.04)$, followed by a double curve $19(0.58)$ and triple curve 5(0.15\%).

\section{Factors influencing AIS}

There were six factors analyzed for this study. Age of menarche for the girls, History of back pain, Schoolbag types, Schoolbag weight, posture during studying, sleeping posture, sitting posture in the classroom. In the analysis of the age of menarche of the 3250 students screened, 39(1.2\%) female students had AIS had menarche after 12 years of age and 19(0.58\%) female students had menarche before 12 years of age. The 58 AIS students, predominantly had menarche age after 12 years $39(67.24 \%)$. This data is represented in table 2.

The bag weight of the AIS students was as following 28 $(0.86 \%)$ students were between $5 \mathrm{~kg}$ and $6 \mathrm{~kg}, 21(0.64 \%)$ students had less 5 kilograms and $5(0.15 \%)$ students. Of 
58 AIS students, students who carried bag weight of 5 to 6 $\mathrm{kg}$ were higher compared to bag weight less than $5 \mathrm{~kg}$ and more than $6 \mathrm{~kg}$, those were 28(48.27\%), 21(36.20\%) and $5(8.6 \%)$ respectively and is represented in table 2.

The type of school bag used consistently was analyzed using a figure containing double sided back bag, and single side bag was shown to the children (figure 1). The children selected one among the bag type, which revealed $47(81 \%)$ students used double sided back bag, and 11(19\%) used single side bags.

The sitting posture of AIS students in the classroom was analyzed. A picture containing five different positions commonly adopted by the student was shown to the students. The students selected one mostly adopted posture. This analysis is shown in table 2 .

Studying posture of AIS students was analyzed by giving three positions as an option, namely sitting, supine lying, and prone lying. The analysis revealed that $29(50 \%)$ preferred sitting, 18(31\%) supine lying, and 11 (19\%) adapted prone lying while studying (table 2).

Sleeping posture of AIS students was analyzed, giving three options, namely prone, supine, and side lying. The analysis revealed that side lying was preferred by $26(44.8 \%)$ students, which was double than the $13(22.4 \%)$ preferred supine lying, and 19(32.7\%) preferred prone lying. 77\% (26 students) of the female students preferred supine lying (table 2).

The history of the previous episode of pain was analyzed which revealed 7(12\%) students out of 58 had a prior history of pain in the curve specific area out of which 5(8.6\%) were girls, and 2(3.4\%) were boys. Out of the seven students, four were having a triple curve (table 2).

Table 1: Demographic data

\begin{tabular}{|ccccccc|}
\hline AGE & $\begin{array}{c}\text { Catego- } \\
\text { ries }\end{array}$ & 11 & 12 & 13 & 14 & 15 \\
$\begin{array}{c}\text { Numbers } \\
\text { (\%) }\end{array}$ & $596(17)$ & $623(18)$ & $723(20)$ & $674(22)$ & $634(23)$ \\
SEX & $\begin{array}{c}\text { Catego- } \\
\text { ries }\end{array}$ & Male & Female & & & \\
& $\begin{array}{c}\text { Number } \\
\text { (\%) }\end{array}$ & $1685(52)$ & $1565(48)$ & & & \\
\hline
\end{tabular}

Table 2: Factors influencing AIS (No.58)

\begin{tabular}{|ccccccc|}
\hline AGE & Categories & 11 & 12 & 13 & 14 & 15 \\
& Percentage & $15 \%$ & $17 \%$ & $28 \%$ & $21 \%$ & $19 \%$ \\
SEX & Categories & Male & Female & & & \\
Curve & Number (\%) & $24(41)$ & $34(59)$ & & & \\
side & Categories & right & left & & & \\
Curve & Number (\%) & $32(55)$ & $26(45)$ & & \\
location & Categories & lumbar & $\begin{array}{c}\text { Thora- } \\
\text { co-lumbar }\end{array}$ & Thoracic & & \\
& Number (\%) & $10(17)$ & $19(33)$ & $29(50)$ & & \\
Number & Categories & 1 & 2 & 3 & & \\
of Curves & Number (\%) & $34(59)$ & $19(33)$ & $5(8)$ & & \\
\hline & & & & &
\end{tabular}

\begin{tabular}{|c|c|c|c|c|c|c|}
\hline $\begin{array}{l}\text { Age of } \\
\text { men- }\end{array}$ & Categories & $\begin{array}{c}<12 \\
\text { years }\end{array}$ & $>12$ years & & & \\
\hline & Number (\%) & $13(38)$ & $21(62)$ & & & \\
\hline $\begin{array}{c}\text { Bag } \\
\text { weight }\end{array}$ & Categories & $<5 \mathrm{~kg}$ & $5-6 \mathrm{~kg}$ & $6-7 \mathrm{~kg}$ & & \\
\hline & Number (\%) & $21(36)$ & $28(48)$ & $9(15)$ & & \\
\hline Bag type & Categories & $\begin{array}{c}\text { double } \\
\text { sided }\end{array}$ & single sided & & & \\
\hline & Number (\%) & $47(81)$ & $11(19)$ & & & \\
\hline $\begin{array}{l}\text { Sitting } \\
\text { posture }\end{array}$ & Categories & A & B & C & D & E \\
\hline & Number (\%) & 10(17) & $02(3)$ & $5(9)$ & $26(45)$ & $15(26)$ \\
\hline $\begin{array}{l}\text { Studing } \\
\text { posture }\end{array}$ & Categories & sitting & supine & prone & & \\
\hline & Number (\%) & $29(50)$ & $18(31)$ & $11(19)$ & & \\
\hline $\begin{array}{l}\text { sleeping } \\
\text { posture }\end{array}$ & Categories & supine & sidelying & prone & & \\
\hline & Number (\%) & $13(22)$ & $26(45)$ & 19(33) & & \\
\hline $\begin{array}{l}\text { History } \\
\text { of back }\end{array}$ & Categories & Yes & No & & & \\
\hline & Number (\%) & $7(12)$ & $51(88)$ & & & \\
\hline
\end{tabular}

\section{DISCUSSION}

In this study, screening was done for 11 to 15 -year students as literature supports this age band to have a more vulnerable population for AIS. During the rapid growth period of the children, the development of AIS curves increases. The progression of the most curves significantly slowed down during the skeletal maturity period, while some curves continue to increase more than $60^{\circ}$ during adulthood [2]. Though there are many reports that screening of large population might lead to needless referrals of adolescent scoliosis with low risk of progression for scoliosis but on the contrary, morbidity rates might increase when referrals are delayed with curves of high-level risk. There are only two studies to the researcher's knowledge being conducted in the past screening for scoliosis in India. On average, the occurrence of scoliosis among both sexes aged from 8 to 14 years was calculated to be $1.8 \%$ to $2.2 \%$ [8-11]. The prevalence rate in north-western and central Greece between the age group 9 and 14 years old among male and female for Cobb's angle $>10^{\circ}$ was found $1.7 \%$, it was also identified that thoracolumbar curve was the not a rare type followed by lumbar scoliosis curves but in the present study lumbar curvature was very meager. In Quebec, among 1000 school children, a prevalence of 42 was found aged from 8 to 15 years. The rate of prevalence survey also reported increasing in girls between age 8 and 15 years, with girls $(51.9 / 1000)$ higher than boys (32.0/1000). The study also highlighted that $31 \%, 37 \%$, and $22.2 \%$ of the curves were situated at the thoracic, thoracolumbar, lumbar, respectively, and $9.5 \%$ had two significant curves [12].

In the present study, the results differed for anatomical curve location, showing the predominant curve in the thoracic spine followed by the thoracolumbar region. The 
female was more vulnerable than the male. There was a significant difference between the AIS at 13 years compared to other age groups. Most of the participants presented with only a single curve followed distantly by double curve and triple curves. $80 \%$ of the subjects who had a triple curve had an episode of pain history and visit to a physician.

In Israel Nussinovitch $M$ et al., in 2002 [13], children who were studying in the local public high school was found to have scoliosis with the prevalence of $1.6 \%\left(\mathrm{Cobb}>11^{\circ}\right)$ with a triple the majority of girls extending above boys between 12 to 18 years old. Girls between 11- to 12-year-old had prevalence rates of $1.37 \%$ for Cobb angle greater than $10^{\circ}, 0.58 \%$ Cobb angle greater than $20^{\circ}$ and $0.21 \%$ Cobb angle greater than $30^{\circ}$. For girls between 13 - and 14-yearold had $2.22 \%$ of prevalence for Cobb angle $>10^{\circ}, 1.25 \%$ Cobb angle $>20^{\circ}$ and $0.52 \%$ Cobb angle greater than $30^{\circ}$ [13]. According to SRS, the need for topographic measurement agreement was not reached by the task force. Recommendation was made by task force that the screening for scoliosis must be performed at the age of 10 and 12 years for females because they can be impaired with magnitude of scoliosis leading to treatment three to four times more frequently than males, since puberty in females is attained about two years before males, in order to capture variation in maturity. Males could be screened once at age 13 to 14 years [3]. This study did not consider cobs angle as the subjects preferred various centers around Chennai for performing X-ray, and few came for review only with the report and did not produce the film.

Scoliotic deformities in another study involved, $40 \%$ of the thoracic region, whereas $30 \%$ of curves in thoracolumbar and $22 \%$ were confined to the lumbar area [13]. In Finland, a study done by Nissinen et al. in 1993 was found that the thoracic region had the most common curves, which were in line with the present study [14]. In a study done in Greece, the common type of curve pattern was found to be the double curve, single thoracolumbar curve, thoracic curves, triple curves and lumbar curves of $39.6 \%, 36.3 \%$, $17.4 \%, 4.3 \%$, and $2.5 \%$ respectively [15].

The limitations of this study were, screening for AIS was done predominantly in government schools in Thiruvallur district. The other limitation was factors that can influence AIS were only analyzed. The forward bend test leads to a high number of false positive referrals having $77.8 \%$ of specificity. Hence there were increased false positive students for AIS.

In further studies, factors determining AIS should be analyzed. The female students who were found to have AIS at 12 to 13 years of age and the students with functional must be followed up for progression or leading to structural scoliosis. A better screening tool with more specificity should be used in future studies to reduce the risk of false positive values or referrals.

\section{CONCLUSION}

This study emphasizes early screening of AIS for school children at the age of eleven- fifteen years based upon the high prevalence rates compared to global standards. Parents and teachers should be aware of the bag type and weight, sitting and studying posture for early prevention of AIS. This study strongly recommends similar screening programs in various geographical limits in India. In addition to this, the government should set reasonable bag weight limits for the corresponding age category.

\section{Abbreviations}

AIS- Adolescent idiopathic scoliosis

FBT- Forward bend test

ATR- Angle of trunk rotation

\section{REFERENCES}

[1] Rothman, RH \&Simeone, FA. The spine, ( $\left.2^{\text {nd }} e d.\right)$. Philadelphia: WB Saunders. 1982. 239-439

[2] Balagué F, Pellisé F. Adolescent idiopathic scoliosis and back pain. Scoliosis Spinal Disord. 2016;11(1):27.

[3] Lonstein JE, Bjorklund S, Wanninger MH. Voluntary school screening for scoliosis in Minnesota. J Bone Joint Surg (Am) 1982; 64:481-488.

[4] Konieczny MR, Senyurt H, Krauspe R. Epidemiology of adolescent idiopathic scoliosis. JchildOrthop. 2013;7: 3-9.

[5] Fan MD and Henguin. Prevalence of idiopathic scoliosis in chinese school children. A large population based study. Spine. 2016; 3: 259-264.

[6] Fred Mo, Mathew E and Cunningham.CurrRevMusculoskelet Med. Pediatric scoliosis .2011; Dec 4(4): 175-182.

[7] Grivas TB, Koukos K, Koukou UI, Maziotou C, Polyzois $\mathrm{BD}$. The incidence of idiopathic scoliosis in Greece - analysis of domestic school screening programs. Stud Health Technol Inform. 2002; 91:71-5.

[8] Wong HK, Hui JH, Rajan U, Chia HP Idiopathic scoliosis in Singapore schoolchildren: a prevalence study 15 years into the screening program. Spine 2005; 30(10):1188-1196.

[9] Kamtsiuris P, Atzpodien K, Ellert U, Schlack R, Schlaud M. Prevalence of somatic diseases in German children and adolescents. Results of the German Health Interview and Examination Survey for Children and Adolescents (KiGGS). BundesgesundheitsblattGesundheitsforschungGesundheitsschutz 2007; 50(5-6):686-700.

[10] Cilli K, Tezeren G, Tas, T, Bulut O, Oztu "rk H, Oztemur Z, Unsaldi $\mathrm{T}$ School screening for scoliosis in Sivas, Turkey. ActaOrthopTraumatolTurc 2009; 43(5):426-430.

[11] Morais T, Bernier M, Turcotte F. Age- and sex-specific prevalence of scoliosis and the value of school screening programs. Am J Public Health 1985;75:1377-80.

[12] Nery LS, Halpern R, Nery PC, Nehme KP, Stein AT. Prevalence of scoliosis among school students in a town in southern Brazil. Sao Paulo Med J 2010 128(2):69-73.

[13] Nussinovitch M, Finkelstein Y, Amir J, Greebaum E, Volovitz B. Adolescent screening for orthopedic problems in high school. Public Health. 2002; 116:30-2.

[14] Nissinen M, Heliovaara M, Seitsamo J, Poussa M. 
Trunk assymmetry, posture, growth and risk of scoliosis. Spine 1993; 8:8-13.

[15] Soucacus PN, Saucacos PK, Zacharis KC, Beris AE. School-screening for scoliosis, a prospective epidemiological study in northwestern and central Greece. J Bone Joint Surg Am.1985; 79:1498503. 